\title{
Role of Gas Type on Foam Transport in Porous Media
}

Yongchao Zeng ${ }^{\dagger}$, Rouhi Farajzadeh ${ }^{\perp} *$, Ali Akbar Eftekhari ${ }^{\perp}$, Sebastien Vincent-Bonnieu ${ }^{\ddagger}$, Aarthi Muthuswamy $^{\dagger}$, William R. Rossen ${ }^{\perp}$, George J. Hirasaki ${ }^{\dagger}$, and Sibani L. Biswal ${ }^{\dagger}$

${ }^{\dagger}$ Rice University, Department of Chemical and Biomolecular Engineering, MS-362, 6200 Main Street, Houston, TX, 77005 USA.

${ }^{\ddagger}$ Shell Global Solutions International, 2288GS Rijswijk, the Netherlands

${ }^{\perp}$ Delft University of Technology, Delft, 2628CN, the Netherlands.

* To whom correspondence should be addressed: email addresses:

biswal@rice.edu and r.farajzadeh@tudelft.nl

\begin{abstract}
We present the results of an experimental investigation of the effect of gas type and composition on foam transport in porous media. Steady-state foam strengths with respect to three cases of distinct gases and two cases containing binary mixtures of these gases were compared. The effects of gas solubility, the stability of lamellae, and the gas diffusion rate across the lamellae were examined. Our experimental results showed that steady-state foam strength is inversely correlated with gas permeability across a liquid lamella, a parameter that characterizes the rate of mass transport. These results are in good agreement with existing observations that the foam strength for a mixture of gases is correlated with the less soluble component. Three hypotheses with different predictions of the underlying mechanism that explain the role of gas type and composition on foam strength are discussed in detail.
\end{abstract}




\section{Introduction:}

There are a number of subsurface applications that utilize gas injection, such as enhanced oil recovery (EOR), aquifer remediation, and hydraulic fracturing ${ }^{1-11}$. However, the efficiency of these applications is limited due to the high mobility of gas, which results in problems like viscous fingering and gravity override ${ }^{12}$. An efficient way to reduce gas mobility is to foam transport the injected gas. Depending on the local availability and gas type, $\mathrm{CO}_{2}, \mathrm{CH}_{4}$, steam, and inert gases like $\mathrm{N}_{2}$ can be injected into subsurface formations ${ }^{13-17}$. Gas mixtures, such as flue gas and light hydrocarbons, can also be injected to avoid the cost of separating these gases into pure gas feeds. The mechanism of how the gas type affects foam transport in porous media remains poorly understood.

Foam in porous media is simply a dispersion of gas in a liquid such that the gas phase is made discontinuous by liquid lamellae films ${ }^{18-20}$. Foam reduces the mobility of the gas phase in porous media in two ways; namely, reducing the mobile gas saturation and increasing the effective viscosity of the gas as a result of added capillary resistance from the liquid lamellae.

At constant temperature and pressure, gas mobility reduction is determined by its constitutive components and the properties of the porous media. Previous research has shown how components in the aqueous phase, such as the surfactant and salts, can affect the stability of foam ${ }^{21-28}$. Additionally, Farajzadeh et al. have discussed the effect of gas type and composition on bulk foam properties ${ }^{29}$. However, few studies have addressed the role of the gas phase on foam in porous media in which liquid lamellae may be generated or collapsed. In this study, we systematically compared steady-state foam strengths in porous media with respect to gas type and composition. 
The gas phase can affect foam strength in several ways. First, different gases have varying solubilities in the aqueous phase, as shown in Table 1 . The ratio of the gas and aqueous phase in foam can be varied, as defined by foam quality: $f_{g}=q_{g} /\left(q_{g}+q_{w}\right)$, where $\mathrm{q}_{\mathrm{g}}$ is the volumetric gas flow rate and $\mathrm{q}_{\mathrm{w}}$ is the volumetric liquid flow rate. Injection of a gas with high solubility in the aqueous phase at the same flow rate as injection of a less water-soluble gas results in a lower foam quality. Thus, the foam strength for gases with different solubilities can vary significantly.

Table 1: Gas Properties for $\mathrm{N}_{2}, \mathrm{CH}_{4}$, and $\mathrm{CO}_{2}$

\begin{tabular}{|c|c|c|}
\hline Gas Type & $\begin{array}{c}\text { Mole Fraction Solubility }{ }^{30} \\
\qquad\left(20^{\circ} \mathrm{C}, 1 \text { bar }\right)\end{array}$ & $\begin{array}{c}\text { Measured Film Permeability } \boldsymbol{k}_{\boldsymbol{f i l m}}{ }^{29,31,32} \\
\text { (Measured at equilibrium film thickness with a } \\
\text { solution of } 4 \mathrm{wt} \% \text { hexadecyl trimethyl ammonium } \\
\text { bromide) }\end{array}$ \\
\hline $\mathrm{N}_{2}$ & $1.2 \mathrm{E}-5$ & 0.13 \\
\hline $\mathrm{CH}_{4}$ & $2.8 \mathrm{E}-5$ & 0.30 \\
\hline $\mathrm{CO}_{2}$ & $70.7 \mathrm{E}-5$ & 7.85 \\
\hline
\end{tabular}

Second, different gases may impact the stability of a single lamella ${ }^{26,33-35}$. Aronson et al. $^{27}$ demonstrated with sodium dodecyl sulfate (SDS) in $\mathrm{NaCl}$ solution that a larger repulsive disjoining pressure $(\boldsymbol{\Pi})$ results in greater flow resistance for foam in porous media. Disjoining pressure arises from the typically repulsive interaction between two surfaces, which balances the capillary pressure and prevents the liquid lamella from rupturing ${ }^{27,36,37}$. Thermodynamically, $\boldsymbol{\Pi}$ can be calculated as the derivative of the surface 
energy per unit area with respect to distance between the pair of interfaces $(\boldsymbol{h})$. If a liquid lamella in foam is considered to be two Gibbs dividing surfaces, as shown in Figure 1, the surface energy can be expressed as the sum of two surface tensions ( $\boldsymbol{\sigma}^{\alpha \gamma}$ and $\boldsymbol{\sigma}^{\boldsymbol{\beta} \gamma}$ ), as shown in Equation $(1)^{38}$. The partial derivative is defined at constant temperature $(\boldsymbol{T})$, chemical potential $\left(\boldsymbol{\eta}_{\boldsymbol{i}}\right)$, and gravitational potential $\left(\boldsymbol{\Phi}_{\text {gravity }}\right)$. The $\boldsymbol{O}(\boldsymbol{H} \boldsymbol{h})$ in Equation (1) denotes the term that is proportional to the product of the mean curvature of the film $(\boldsymbol{H})$ and the thickness $(\boldsymbol{h})$, and is equal to zero for a flat lamella when $\boldsymbol{H}$ is negiligible. Different gas types can result in varied disjoining pressures because of the differences in intermolecular interactions.

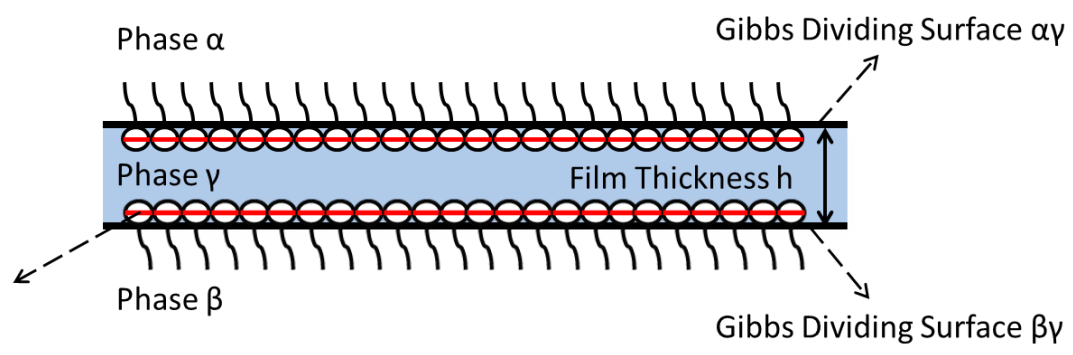

Figure 1: Gibbs dividing surfaces for foam film.

$$
\boldsymbol{\Pi}=\left[\frac{\partial\left(\boldsymbol{\sigma}^{\alpha \gamma}+\boldsymbol{\sigma}^{\beta \gamma}\right)}{\partial \boldsymbol{h}}\right]_{T, \eta_{i}, \Phi_{\text {gravity }}}+\boldsymbol{O}(\boldsymbol{H h})
$$

Lastly, gas type affects the coarsening of the foam due to the differences in gas diffusion across the liquid lamella ${ }^{25,39,40}$. As shown in Equation (2), the rate of gas molecules diffusing across the liquid lamella $\left(\frac{d N}{d t}\right)$, is proportional to the gas concentration difference $(\Delta \boldsymbol{C})$ and the area of the lamella $(\boldsymbol{A})^{31}$. The gas permeability $\left(\boldsymbol{k}_{\boldsymbol{f i l m}}\right)$ is a transport property that varies with gas type ${ }^{21}$. Thus, different gases have different rates of 
mass transport from small to large bubbles. The measured film permeability to different gases is given in Table 1.

$$
\frac{d N}{d t}=-k_{f i l m} A \Delta C
$$

It has been suggested that mass transfer is the main mechanism responsible for coarsening in steam foams, where water condenses on one side and evaporates from the other side of the lamella ${ }^{41}$. Such mass transfer is faster than simple diffusion, where gas molecules need to first dissolve and then diffuse through the liquid film. More recently, Farajzadeh et al. ${ }^{42}$ found that bulk foam stability is very well correlated with the rate of gas diffusion through the lamellae. However, the role of gas diffusion within foam inside porous media is not clearly understood. Nonnekes et al. ${ }^{43}$ found that bubbles smaller than pore space will quickly coarsen to approximately the pore size, indicating that gas diffusion is not the only mechanism responsible for foam stability.

\section{Materials and Methods}

Alpha olefin sulfonate $\mathrm{C} 14-16\left(\mathrm{AOS}_{\mathrm{C} 14-16}\right.$, Stepan) was chosen as the foaming agent because of its success in a pilot test in the Snorre oil field in Norway ${ }^{1,2,21,44}$. The properties of the solution and single foam films stabilized by this surfactant have been previously described. ${ }^{45} \mathrm{AOS}_{\mathrm{C} 14-16}$ was diluted to $1 \mathrm{wt} \%$ in synthetic seawater, which had a composition of $0.67 \mathrm{~g} / \mathrm{L} \mathrm{KCl}, 10.15 \mathrm{~g} / \mathrm{L} \mathrm{MgCl}_{2} \cdot 6 \mathrm{H}_{2} \mathrm{O}, 1.47 \mathrm{~g} / \mathrm{L} \mathrm{CaCl}{ }_{2} \cdot 2 \mathrm{H}_{2} \mathrm{O}, 3.83 \mathrm{~g} / \mathrm{L}$ $\mathrm{Na}_{2} \mathrm{SO}_{4}$, and $25.21 \mathrm{~g} / \mathrm{L} \mathrm{NaCl}$. All aqueous solutions were prepared in deionized water. 
Gases used in the experiments were $\mathrm{N}_{2}, \mathrm{CH}_{4}, \mathrm{CO}_{2}$, flue gas $\left(80 \mathrm{~mol} \% \mathrm{~N}_{2}\right.$ and $20 \mathrm{~mol} \%$ $\mathrm{CO}_{2}$ ), and $\mathrm{CH}_{4}-\mathrm{CO}_{2}$ mixtures $\left(50 \mathrm{~mol} \% \mathrm{CH}_{4}\right.$ and $\left.50 \mathrm{~mol} \% \mathrm{CO}_{2}\right)$. Bentheimer sandstone, which is mainly composed of quartz, was used as the core material. It is a homogeneous porous medium with a measured absolute permeability of 2.3 Darcy with respect to water. The specifications of the core sample are listed in Supplemental Information Table S1. The core was coated with a 2-mm layer of Araldite resin to prevent bypassing. Next, the core was mounted to a cylindrical PEEK (polyether ether ketone) core holder. ${ }^{46} \mathrm{~A}$ schematic of the experimental setup can be found in Deal Information Figure S1. Gas was injected into the inlet of the core through a mass flow controller. The surfactant solution was injected in parallel through a Quizix pump (Vindum QX6000HC-0-0-C-L-0). A back pressure regulator (Eigen merk CTS MB420) was connected to the outlet of the core holder $^{46-48}$.

The experimental protocol was to first inject $\mathrm{CO}_{2}$ gas at 5 bar to displace air inside the core. Next, the pressure was raised to 25 bar and at least 10 pore volumes (PVs) of water were injected to dissolve all the $\mathrm{CO}_{2}$. Then, $5 \mathrm{PVs}$ of surfactant solution were injected to saturate the core and satisfy the adsorption capacity of the rock. Finally, the back pressure was set to 21 bar and surfactant solution was co-injected with gas until a steady-state foam strength was obtained. The total pressure drop across the core was recorded during the experiment. During the foam-flooding experiment, the total superficial velocity was held at $4 \mathrm{ft} / \mathrm{day}$ and back pressure at 21 bar. Experiments were conducted at ambient temperature. To eliminate the effect of permeability differences, the same core was utilized when switching the gas type. To remove the previous gas, $5 \mathrm{PVs}$ of isopropanol were injected to destroy the foam, then $20 \mathrm{PVs}$ of water were injected to displace the 
alcohol, and then $\mathrm{CO}_{2}$ was re-injected to displace the remaining gas. Permeability was remeasured each time with water to ensure the system was fully saturated with liquid.

\section{Results and Discussion}

In our study, the strength of foam in porous media was quantified by apparent viscosity $\left(\boldsymbol{\mu}_{\boldsymbol{a p p}}\right)$ as defined in Equation (3) $)^{49}$. Apparent viscosity can be interpreted as flow resistance that is measured as pressure gradient $(\nabla \boldsymbol{p})$ and normalized with permeability $\left(\boldsymbol{k}_{\text {rock }}\right)$ and total superficial velocity $\left(\boldsymbol{u}_{\text {total }}\right)$. Higher $\boldsymbol{k}_{\text {rock }}$ leads to stronger foam, due to the lower capillary pressure between gas and liquid phases, and reduces the likelihood of rupturing the foam film. A higher $\boldsymbol{u}_{\text {total }}$ leads to less strong foam due to the shearthinning rheological property of foam flow.

$$
\mu_{\text {app }}=-\frac{\boldsymbol{k}_{\text {rock }}}{\boldsymbol{u}_{\text {total }}} \nabla p
$$

Representative experimental results for the pure gas systems are shown in Figure 2. The apparent viscosity and pressure gradient are shown as a function of foam quality, which allows comparison of the effects of flow resistance for different gas types on foam with varying gas fractions while keeping total superficial velocity constant. The gas volumetric flow rate is calculated from the back pressure measurement. Because of the compressibility of the gas, the foam quality at the inlet is somewhat lower than the calculated value. 


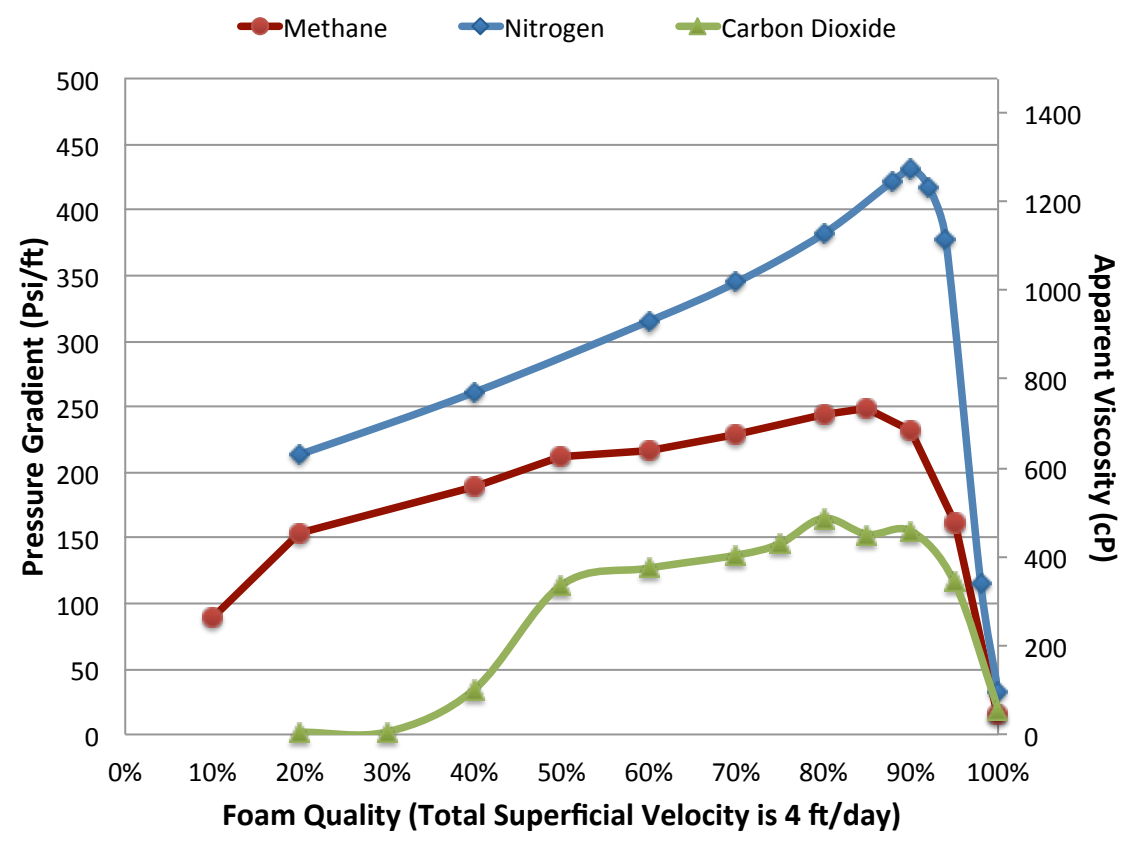

Figure 2: Foam strength as a function of foam quality for various gases: nitrogen (diamond), methane (circles), and carbon dioxide (triangles).

We observed both low- and high-quality regimes for each gas, which were separated by the transition foam quality at the point of maximum apparent viscosity ${ }^{50}$. In the lowquality regime, the resistance to flow was determined by bubble trapping and mobilization, and foam strength was observed to increase as foam quality increased. In the high-quality regime, foam strength decreased as the foam quality increased due to constraints of limiting capillary pressure and bubble coalescence ${ }^{24}$. For a fixed foam quality, we found that $\mathrm{N}_{2}$ foam had the maximum steady-state foam strength, followed by $\mathrm{CH}_{4}$ foam and $\mathrm{CO}_{2}$ foam. Three hypotheses are discussed below to probe the underlying mechanism that explains the observed effects of gas type on steady-state foam strength.

\subsection{Hypothesis I: Gas Solubility}


Given that different types of gases have different solubilities in the aqueous phase, one hypothesis is that the actual foam quality is lower than the injected quality for a gas with high solubility. Thus, steady-state foam strengths are different. Control experiments were performed with $\mathrm{CO}_{2}$ because $\mathrm{CO}_{2}$ has the maximum solubility in water (almost 60 times higher than $\mathrm{N}_{2}$ and 30 times higher than $\mathrm{CH}_{4}$ ). The amount of dissolved gas was compensated by either saturating the surfactant solution with $\mathrm{CO}_{2}$ or by increasing gas flow rate $\left(Q_{g}\right)$ in the control steady-state experiments.

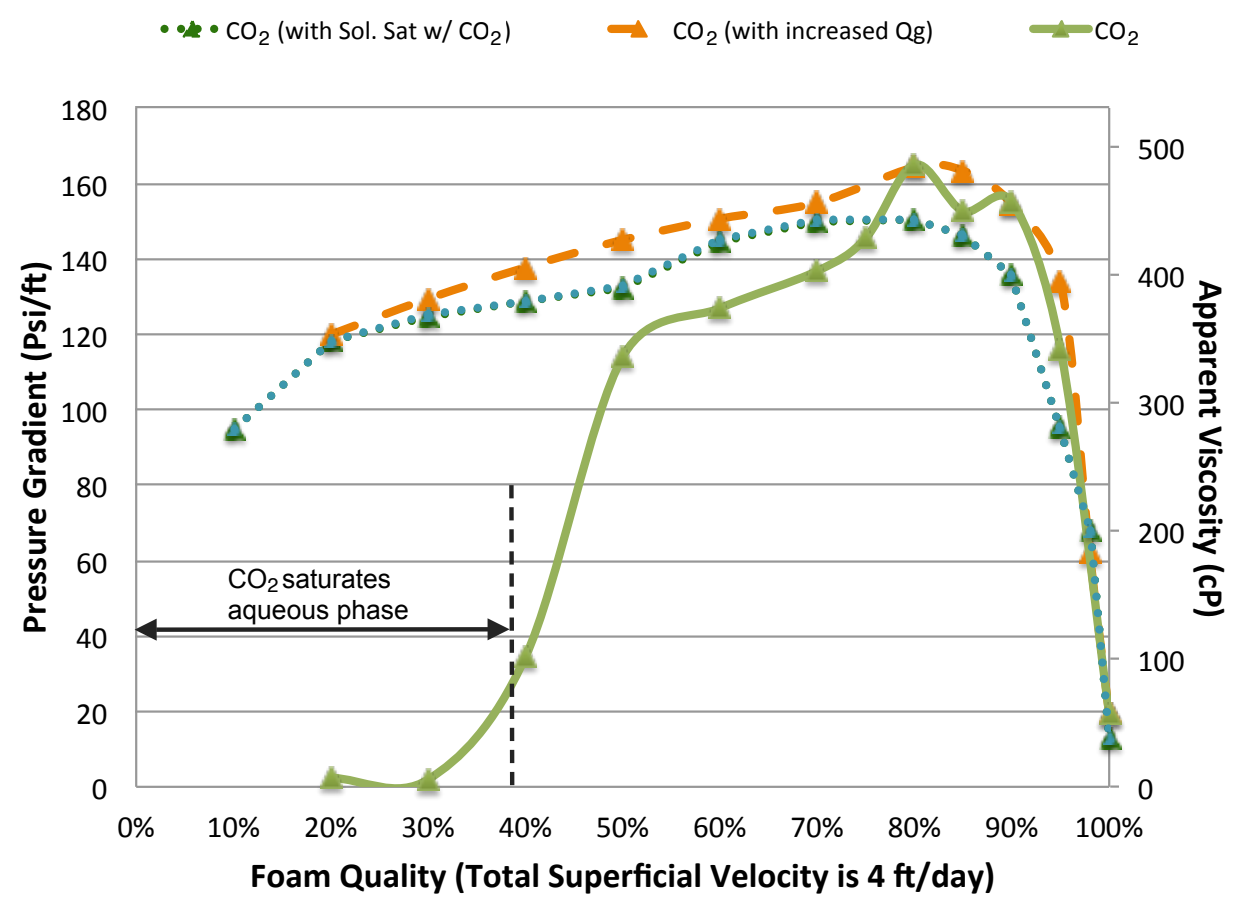

Figure 3: Foam quality scans for $\mathrm{CO}_{2}$ under various conditions. Increasing the $\mathrm{CO}_{2}$ flow rate compensates for dissolved $\mathrm{CO}_{2}$ in the aqueous phase (dashed line) or saturating the aqueous solution with $\mathrm{CO}_{2}$ (dotted line) results in stronger foam at lower foam qualities compared to $\mathrm{CO}_{2}$ gas (solid line). An increase in foam apparent viscosity is observed once the $\mathrm{CO}_{2}$ is saturated in the aqueous phase. 
The solid curve in Figure 3 shows that as foam quality (or gas fractional flow) decreases, a larger fraction of injected $\mathrm{CO}_{2}$ is dissolved in the aqueous phase. When the foam quality is reduced to $40 \%$ or less, the injected $\mathrm{CO}_{2}$ would dissolve completely if the surfactant solution was not pre-saturated with $\mathrm{CO}_{2}$ or the gas flow rate was not increased to compensate. However, both dashed curves in Figure 3 show that the gas solubility has a negligible effect in the high-quality regime. Compensating $\mathrm{CO}_{2}$ dissolved in the aqueous phase failed to generate $\mathrm{CO}_{2}$ foam that is as strong as $\mathrm{N}_{2}$ or $\mathrm{CH}_{4}$ at steady state.

\section{Hypothesis II: Stability of the Lamella}

We hypothesized that steady-state foam strength is influenced by the effect of gas type on the stability of the liquid lamella, which is related to the disjoining pressure. Excluding non-DLVO forces ${ }^{51}$, disjoining pressure can be decomposed into two parts, electrostatic repulsion $\left(\boldsymbol{\Pi}_{\boldsymbol{e}}\right)$ and van der Waals attraction $\left(\boldsymbol{\Pi}_{v \boldsymbol{w}}\right)$, as shown in Equation (4).

$$
\boldsymbol{\Pi}=\boldsymbol{\Pi}_{e l}+\boldsymbol{\Pi}_{v w}
$$

The electrostatic contribution to the disjoining pressure arises from charged surfactant molecules packing the two neighboring gas-liquid interfaces and is mainly a function of surfactant packing density and the salinity of the liquid phase ${ }^{45,52}$. Tighter packing of the surfactant molecules will result in stronger repulsive interactions between the two interfaces, thus better stabilizing the foam film against rupture. The salinity in the liquid phase determines the Debye length and directly influences the packing density at the interface. There is no direct evidence that different gas molecules can significantly affect 
either the surfactant packing or the salinity of the liquid phase. Therefore, we investigated only the variation in $\boldsymbol{\Pi}_{\boldsymbol{w}}$ due to the difference in intermolecular forces in the gas phases.

We can roughly estimate the van der Waals contribution by assuming that all the gases obey the van der Waals equation of state as shown in Equation $(5)^{53}$. Thus, the pair potential between two molecules $[\boldsymbol{w}(\boldsymbol{r})]$ can be expressed as shown in Equation $(6)^{54}$. The pair potential coefficient $(\boldsymbol{c})$ can be calculated from the attraction coefficient $(\boldsymbol{a})$ and the van der Waals diameter $\left(\boldsymbol{\sigma}_{v \boldsymbol{w})}\right)$ as shown in Equation $(7)^{54}$.

$$
\begin{gathered}
\left(p+\frac{a}{V_{m}^{2}}\right)\left(V_{m}-b\right)=R T \\
w(r)=-\frac{c}{r^{6}} \\
c=\frac{3 a \sigma_{v w}^{3}}{2 \pi N_{A}}
\end{gathered}
$$

\begin{tabular}{|c|c|c|c|c|}
\hline Gas Type & $\begin{array}{c}\boldsymbol{a}^{37,38} \\
\text { Pa.m } \mathrm{m}^{6} \cdot \mathrm{mol}^{-2}\end{array}$ & $\begin{array}{c}\boldsymbol{b}^{37,38} \\
\mathrm{~m}^{3} / \mathrm{mol} \\
\end{array}$ & $\begin{array}{c}\boldsymbol{\sigma}_{\boldsymbol{v} \boldsymbol{w}} \\
\text { (Calculated from } \boldsymbol{b}) \\
\AA \\
\AA\end{array}$ & $\begin{array}{c}c \\
\text { (Calculated from Equation 7) } \\
\text { J.m } \\
\end{array}$ \\
\hline $\mathrm{N}_{2}$ & 0.141 & $3.91 \mathrm{E}-5$ & 4.99 & $2.3 \mathrm{E}-77$ \\
\hline $\mathrm{CH}_{4}$ & 0.228 & $4.28 \mathrm{E}-5$ & 5.14 & $4.1 \mathrm{E}-77$ \\
\hline $\mathrm{CO}_{2}$ & 0.364 & $4.27 \mathrm{E}-5$ & 5.14 & $6.5 \mathrm{E}-77$ \\
\hline
\end{tabular}

Table 2: van der Waals Coefficients $\boldsymbol{a}$ and $\boldsymbol{b}$, van der Waals Diameter $\boldsymbol{\sigma}_{\boldsymbol{v} \boldsymbol{w}}$, and Pair Potential Coefficient $\boldsymbol{c}$ for Different Types of Gases

We further assume that the pair potential is non-retarded and additive. The "two-body" potential for two flat surfaces interacting in a vacuum is described by Equation $(8)^{54}$, 
where $\boldsymbol{W}_{\boldsymbol{v}}(\boldsymbol{h})$ is van der Waals interaction potential between two parallel surfaces across a vacuum and $\boldsymbol{A}_{\mathbf{1 1}}$ is the Hamaker constant. As shown in Equation $(9)^{54}, \boldsymbol{A}_{\mathbf{1 1}}$ can be correlated with van der Waals pair potential coefficient $(\boldsymbol{c})$ and the number density of molecules $\left(\boldsymbol{\rho}_{\mathbf{1}}\right)$, which can be determined from the van der Waals equation of state.

$$
W_{v w}(h)=-\frac{A_{11}}{12 \pi h^{2}}
$$

$$
A_{11}=\pi^{2} c \rho_{1}^{2}
$$

To calculate $\boldsymbol{A}_{\mathbf{1 1}}$ for two parallel surfaces with an aqueous phase sandwiched in between, we applied the combining relation ${ }^{54}$ by assuming $A_{13}$ equals the geometric mean of $\boldsymbol{A}_{\mathbf{1 1}}$ and $\boldsymbol{A}_{33}$ as shown in Equation (10). Here we neglect the effect of dissolved electrolytes on the $\boldsymbol{A}_{\mathbf{1 1}}$ for water.

$$
A_{131} \approx A_{11}+A_{33}-2 A_{13} \approx\left(\sqrt{A_{11}}-\sqrt{A_{33}}\right)^{2}
$$

Table 3: Hamaker Constant for Parallel Surfaces Interacting between Pure Water

\begin{tabular}{|c|c|c|}
\hline Material & $\boldsymbol{A}_{\mathbf{1 1}}(\mathrm{J}) 21$ bar $20^{\circ} \mathrm{C}$ & $\boldsymbol{A}_{\mathbf{1 3 1}}(\mathrm{J}) 21$ bar $20^{\circ} \mathrm{C}$ \\
\hline $\mathrm{N}_{2} \mid$ Water $\mid \mathrm{N}_{2}$ & $3.8 \mathrm{E}-22$ & $3.40 \mathrm{E}-20$ \\
\hline $\mathrm{CH}_{4} \mid$ Water $\mid \mathrm{CH}_{4}$ & $7.9 \mathrm{E}-22$ & $3.29 \mathrm{E}-20$ \\
\hline $\mathrm{CO}_{2} \mid$ Water $\mid \mathrm{CO}_{2}$ & $20.3 \mathrm{E}-22$ & $3.15 \mathrm{E}-20$ \\
\hline Water & & \\
\hline & $370.0 \mathrm{E}-22$ & \\
\hline
\end{tabular}


The van der Waals force contribution to the disjoining pressure can be calculated by taking the derivative of the van der Waals potential $\left(\boldsymbol{\Pi}_{\boldsymbol{v}}\right)$ with respect to film thickness, as shown in Equation (11).

$$
\Pi_{v w}=-\frac{d W_{v w}(h)}{d h}
$$

For a given film thickness $\boldsymbol{h}$, a larger Hamaker constant $\boldsymbol{A}_{\mathbf{1 3 1}}$ indicates stronger van der Waals forces, which can more easily destabilize foam lamellae. As a result, the calculated Hamaker constants indicate that $\mathrm{CO}_{2}$ should have the most stable foam, whereas $\mathrm{N}_{2}$ should have the least stable foam. This conclusion agrees with Kibodeaux's dissertation ${ }^{55}$, but is contrary to our experimental observation. This discrepancy may be a result of the following factors: (1) significant differences in the equilibrium film thickness $\boldsymbol{h}$ for different types of gases; (2) the surface potential at the gas-liquid interface varies with gas type; and (3) solvation structural and hydration forces that may be contributing factors other than DLVO forces.

\subsection{Hypothesis III: Diffusion Coarsening}

Our third hypothesis argues that steady-state foam strength is determined by the rate of gas transfer across a foam lamella. Different gases have varied permeabilities $\left(\boldsymbol{k}_{\boldsymbol{f i l m}, \boldsymbol{i}}\right)$ through the lamella, thereby changing the rate of mass transfer between small and large bubbles. As a result, bubbles coalesce at different rates. Because our experimental observation revealed that $\mathrm{N}_{2}$ foam has the maximum steady-state foam strength, we realize that such change in apparent viscosity is in accordance with the change in film 
permeability listed in Table 1. To further test this hypothesis, two more sets of experiments were performed with binary gas mixtures. The first mixture was a flue gas with $\mathrm{N}_{2}$ and $\mathrm{CO}_{2}$ in an $8: 2 \mathrm{~mol} \%$ ratio and the second was a $\mathrm{CO}_{2}$ and $\mathrm{CH}_{4}$ gas mixture in a $1: 1 \mathrm{~mol} \%$ ratio.

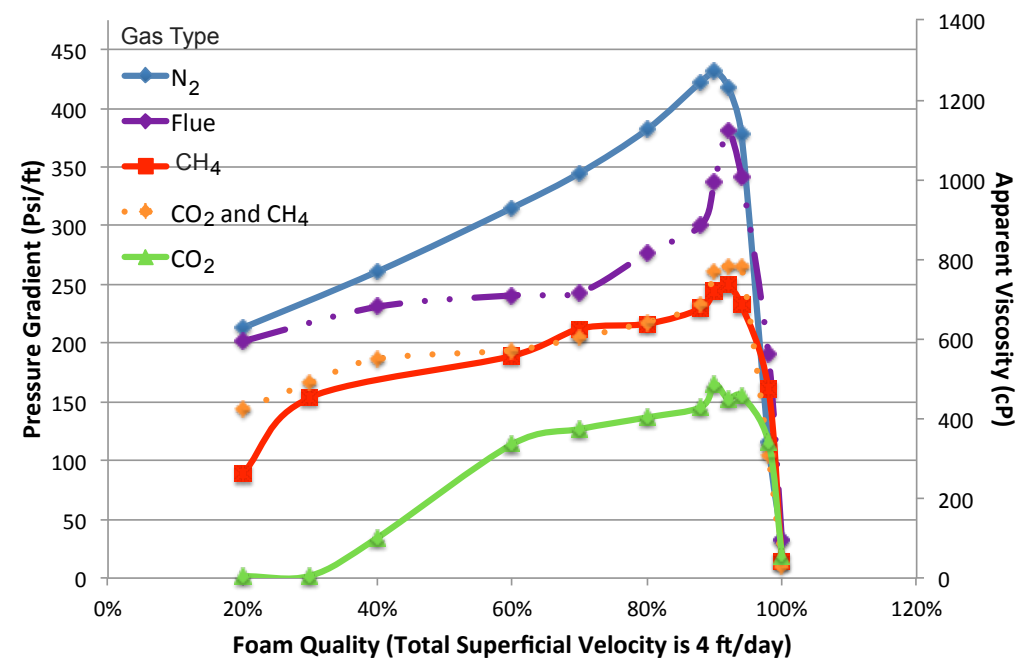

Figure 4: Foam quality scan for $\mathrm{N}_{2}, \mathrm{CH}_{4}, \mathrm{CO}_{2}$, and their binary mixtures.

Nitrogen gas (solid diamond) had the strongest foam strength, followed by flue ( 80 mol $\% \mathrm{~N}_{2}$ and $20 \mathrm{~mol} \% \mathrm{CO}_{2}$ ) gas (dashed diamond), $50 \mathrm{~mol}^{2} \mathrm{CH}_{4}$ and $50 \mathrm{~mol} \%$ $\mathrm{CO}_{2}$ (dotted triangle), $\mathrm{CH}_{4}$ (square); and $\mathrm{CO}_{2}$ (solid triangle). The strength of the mixed gas foams corresponds with foams of the least soluble gas.

As shown in Figure 4, the mixture of $50 \mathrm{~mol}^{2} \mathrm{CH}_{4}$ and $50 \mathrm{~mol} \% \mathrm{CO}_{2}$ has approximately the same foam strength as the less soluble gas $\mathrm{CH}_{4}$. Similarly, the flue gas curve overlaps the $\mathrm{N}_{2}$ curve for qualities higher than $90 \%$ in the $\mathrm{N}_{2}$ and $\mathrm{CO}_{2}$ mixture in the high-quality regime. The mixture has slightly lower foam strength than $\mathrm{N}_{2}$ in the low- 
quality regime. This result is in agreement with the industrial practice to add a small amount of non-condensable gases, such as $\mathrm{N}_{2}$, to boost the strength of steam foam ${ }^{41}$. Princen and Mason proposed that the film permeability of a mixed gas $\left.\overline{\boldsymbol{k}}_{\text {film,mixture }}\right)$ can be approximated as the harmonic mean permeability of its constitutive components $\left(\boldsymbol{k}_{\boldsymbol{f i l m}, \boldsymbol{i}}\right)$ as shown in Equation (12) $)^{31}$, where $\boldsymbol{x}_{\boldsymbol{i}}$ is the mole fraction of component $\boldsymbol{i}$ in the gas phase. We define relative foam strength here in Equation (13) as normalized foam apparent viscosity with respect to $\mathrm{N}_{2}$ foam at constant absolute permeability $\left(\boldsymbol{k}_{\text {rock }}\right)$, foam quality, total flux, temperature, and pressure. The relative foam strength is significantly correlated with film permeability to different gases $\left(\boldsymbol{k}_{\boldsymbol{f} i l m, i}\right)$. As shown in Figure 5, foam strength decays with increasing film permeability.

$$
\begin{gathered}
\overline{\boldsymbol{k}}_{\text {film,mixture }}=\frac{1}{\sum_{i=1}^{n} \frac{x_{i}}{k_{f i l m, i}}} \\
\text { Relative Foam Strength }=\left(\frac{\mu_{a p p, i}}{\mu_{a p p, N_{2}}}\right)_{k_{\text {rock }, f_{g}, u, T, p}}
\end{gathered}
$$




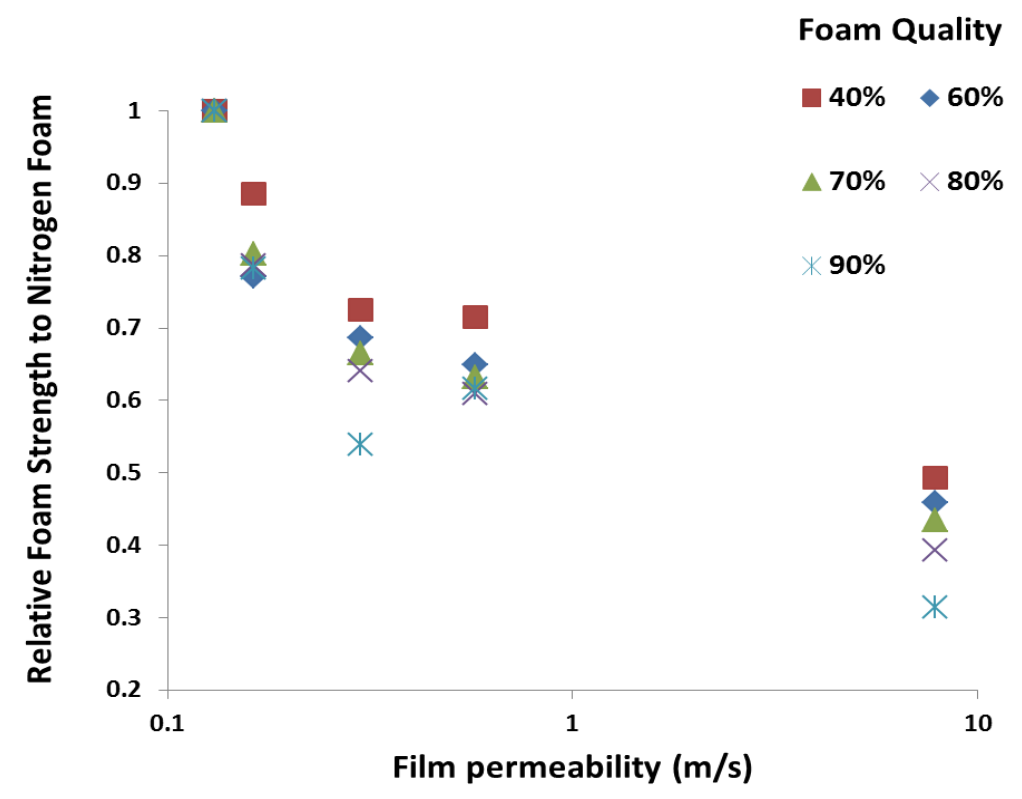

Figure 5: Relative foam strength to $\mathrm{N}_{2}$ as a function of film permeability. Different symbols represent various foam qualities ranging from $40-90 \%$.

\section{Conclusion}

Steady-state foam experiments through porous media using $\mathrm{N}_{2}, \mathrm{CH}_{4}, \mathrm{CO}_{2}$, and two binary gas mixtures were conducted using Bentheimer sandstone at ambient temperature and 21 bar. Under these conditions, we observed that foam apparent viscosity decreases in the order of $\mathrm{N}_{2}$, flue gas, $\mathrm{CH}_{4}, \mathrm{CH}_{4} / \mathrm{CO}_{2}$ mixture, and $\mathrm{CO}_{2}$. The differences in gas solubility, lamella stability, and film permeability were examined. Firstly, we confirmed that gas solubility is not the main cause accounting for the difference in foam strength in porous media. Secondly, we found that the van der Waals force contribution to disjoining pressure gives a contradicting prediction of lamella stability to explain the role of gas type on foam apparent viscosity. Thirdly, we discovered a strong correlation between foam 
strength in porous media and the measured film permeability to different types of gas $\boldsymbol{k}_{\boldsymbol{f i l m}, \boldsymbol{i}}$. Further investigation is needed to experimentally determine the exact nature of this correlation.

\section{Acknowledgement}

We acknowledge financial support from Rice University Consortium for Processes in Porous Media (Houston, TX, USA), Delft University of Technology (Delft, the Netherlands), and Shell Global Solutions International (Rijswijk, the Netherlands). We thank Professor Clarence A. Miller for insightful discussions. Ing. M. (Michiel) Slob is gratefully acknowledged for his technical support of the lab setup. We also extend our thanks to Dr. K.H.A.A. Wolf, P.M. (Ellen) Meijvogel-de Koning, J. (Jolanda) van Haagen-Donker, M. (Marc) Friebel, D. (Dirk) Delforterie, and H.G. (Henk) van Asten for their assistance in completing the experiments.

\section{Supporting Information Available}

Supplemental information on the core properties and experimental setup for foam flooding is provided. This information is available free of charge via the Internet at http://pubs.acs.org/.

\section{References}

(1) Svorstol, I.; Vassenden, F.; Mannhardt, K. Laboratory Studies for Design of a Foam Pilot in the Snorre Field; Society of Petroleum Engineers: SPE, 1996.

(2) Spirov, P.; Rudyk, S.; Khan, A. Foam Assisted WAG, Snorre Revisit with New Foam Screening Model; Society of Petroleum Engineers: SPE, 2012.

(3) Blaker, T.; Aarra, M. G.; Skauge, A.; Rasmussen, L.; Celius, H. K.; Martinsen, H. A.; Vassenden, F. Foam for Gas Mobility Control in the Snorre Field: The FAWAG Project. SPE Reserv. Eval. Eng. 2002, 5 (04), 317-323. 
(4) Harpole, K. J.; Siemers, W. T.; Gerard, M. G. CO2 Foam Field Verification Pilot Test at EVGSAU: Phase IIIC--Reservoir Characterization and Response to Foam Injection; Society of Petroleum Engineers, 1994.

(5) Martin, F. D.; Heller, J. P.; Weiss, W. W.; Tsau, J.-S.; Zornes, D. R.; Sugg, L. A.; Stevens, J. E.; Kim, J. E. CO2-Foam Field Verification Pilot Test at EVGSAU Injection Project Phase I: Project Planning and Initial Results; Society of Petroleum Engineers, 1992.

(6) Stevens, J. E.; Harpole, K. J.; Zornes, D. R.; Martin, F. D. CO2 Foam Field Verification Pilot Test at EVGSAU: Phase II - Foam Injection Design and Operating Plan; Society of Petroleum Engineers, 1992.

(7) Tsau, J.-S.; Heller, J. P. CO2 Foam Field Verification Pilot Test at EVGSAU: Phase IIIA-Surfactant Performance Characterization and Quality Assurance; Society of Petroleum Engineers, 1994.

(8) Stevens, J. E. CO2 Foam Field Verification Pilot Test at EVGSAU: Phase IIIB--Project Operations and Performance Review. SPE Reserv. Eng. 1995, 10 (04), 266-272.

(9) Sun, Q.; Li, Z.; Li, S.; Jiang, L.; Wang, J.; Wang, P. Utilization of Surfactant-Stabilized Foam for Enhanced Oil Recovery by Adding Nanoparticles. Energy Fuels 2014, 28 (4), 2384-2394.

(10) Zhu, T.; Ogbe, D. O.; Khataniar, S. Improving the Foam Performance for Mobility Control and Improved Sweep Efficiency in Gas Flooding. Ind. Eng. Chem. Res. 2004, 43 (15), 4413-4421.

(11) Lv, Q.; Li, Z.; Li, B.; Li, S.; Sun, Q. Study of Nanoparticle-Surfactant-Stabilized Foam as a Fracturing Fluid. Ind. Eng. Chem. Res. 2015, 54 (38), 9468-9477.

(12) Lake, L.; Johns, R.; Rossen, W. R.; Pope, G. Fundementals of Enhanced Oil Recovery; Society of Petroleum Engineers, 2014.

(13) Aarra, M. G.; Ormehaug, P. A.; Skauge, A.; Masalmeh, S. K.; others. Experimental Study of CO2-and Methane-Foam Using Carbonate Core Material at Reservoir Conditions. In SPE Middle East Oil and Gas Show and Conference; Society of Petroleum Engineers, 2011.

(14) Hirasaki, G. J.; others. Supplement to SPE 19505 The Steam-Foam Process-Review of Steam-Foam Process Mechanisms. 1989.

(15) Simjoo, M. Immiscible Foam for Enhancing Oil Recovery. Pet. Eng. 2012, 187.

(16) Wang, J.; Liu, H.; Ning, Z.; Zhang, H. Experimental Research and Quantitative Characterization of Nitrogen Foam Blocking Characteristics. Energy Fuels 2012, 26 (8), 5152-5163.

(17) Lee, H. O.; Heller, J. P. Carbon Dioxide_Foam Mobility Measurements at High Pressure. In Surfactant-Based Mobility Control; Smith, D. H., Ed.; American Chemical Society: Washington, DC, 1988; Vol. 373, pp 375-386.

(18) Falls, A.; Hirasaki, G.; Patzek, T. e al; Gauglitz, D.; Miller, D.; Ratulowski, T. Development of a Mechanistic Foam Simulator: The Population Balance and Generation by Snap-Off. SPE Reserv. Eng. 1988, 3 (03), 884-892.

(19) Shirley, A. I. Foam Formation in Porous Media: A Microscopic Visual Study. In Surfactant-Based Mobility Control; Smith, D. H., Ed.; American Chemical Society: Washington, DC, 1988; Vol. 373, pp 234-257.

(20) Solbakken, J. S.; Skauge, A.; Aarra, M. G. Foam Performance in Low Permeability Laminated Sandstones. Energy Fuels 2014, 28 (2), 803-815.

(21) Svorstoel, I.; Blaker, T.; Arneson, S.; Holt, T.; Vassenden, F.; M. Surguchev, L. Foam Pilot Evaluations for the Snorre Field, Part 1: Project and Laboratory Results; 1995. 
(22) Liu, Y.; Grigg, R. B.; Bai, B. Salinity, pH , and Surfactant Concentration Effects on CO2Foam. In SPE-93095-MS; Society of Petroleum Engineers: SPE, 2005.

(23) Micheau, C.; Bauduin, P.; Diat, O.; Faure, S. Specific Salt and pH Effects on Foam Film of a pH Sensitive Surfactant. Langmuir 2013, 29 (27), 8472-8481.

(24) Muruganatha; Krastev, R.; Müller, H.-J.; Möhwald, H. Foam Films Stabilized with Dodecyl Maltoside. 2. Film Stability and Gas Permeability. Langmuir 2006, 22 (19), 79817985.

(25) Krustev, R.; Müller, H. J. Effect of Film Free Energy on the Gas Permeability of Foam Films. Langmuir 1999, 15 (6), 2134-2141.

(26) Bergeron, V. Disjoining Pressures and Film Stability of Alkyltrimethylammonium Bromide Foam Films. Langmuir 1997, 13 (13), 3474-3482.

(27) Aronson, A. S.; Bergeron, V.; Fagan, M. E.; Radke, C. J. The Influence of Disjoining Pressure on Foam Stability and Flow in Porous Media. Colloids Surf. Physicochem. Eng. Asp. 1994, 83 (2), 109-120.

(28) Lobo, L.; Wasan, D. T. Mechanisms of Aqueous Foam Stability in the Presence of Emulsified Non-Aqueous-Phase Liquids: Structure and Stability of the Pseudoemulsion Film. Langmuir 1993, 9 (7), 1668-1677.

(29) Farajzadeh, R.; Vincent-Bonnieu, S.; Bourada Bourada, N. Effect of Gas Permeability and Solubility on Foam. J. Soft Matter 2014, 2014, 1-7.

(30) Lide, D. R. CRC Handbook of Chemistry and Physics: A Ready-Reference Book of Chemical and Physical Data.; CRC Press: Boca Raton, Fla., 2003.

(31) Princen, H. M.; Mason, S. G. The Permeability of Soap Films to Gases. J. Colloid Sci. 1965, 20 (4), 353-375.

(32) Princen, H. .; Overbeek, J. T. .; Mason, S. . The Permeability of Soap Films to Gases. J. Colloid Interface Sci. 1967, 24 (1), 125-130.

(33) Andersson, G.; Carey, E.; Stubenrauch, C. Disjoining Pressure Study of Formamide Foam Films Stabilized by Surfactants. Langmuir 2010, 26 (11), 7752-7760.

(34) Bergeron, V.; Waltermo, Å.; Claesson, P. M. Disjoining Pressure Measurements for Foam Films Stabilized by a Nonionic Sugar-Based Surfactant. Langmuir 1996, 12 (5), 1336-1342.

(35) Buchavzov, N.; Stubenrauch, C. A Disjoining Pressure Study of Foam Films Stabilized by Mixtures of Nonionic and Ionic Surfactants. Langmuir 2007, 23 (10), 5315-5323.

(36) Exerowa, D.; Kolarov, T.; Khristov, K. Direct Measurement of Disjoining Pressure in Black Foam Films. I. Films from an Ionic Surfactant. Colloids Surf. 1987, 22 (2), 161-169.

(37) Bergeron, V.; Radke, C. J. Disjoining Pressure and Stratification in Asymmetric ThinLiquid Films. Colloid Polym. Sci. 1995, 273 (2), 165-174.

(38) Hirasaki, G. J. Thermodynamics of Thin Films and Three-Phase Contact Regions. In Interfacial Phenomena in Petroleum Recovery; Norman, M., Ed.; Surfactant Science Series; Marcel Dekker: New York, 1991; Vol. 36, pp 23-99.

(39) Andreatta, G.; Lee, L.-T.; Lee, F. K.; Benattar, J.-J. Gas Permeability in Polymer- and Surfactant-Stabilized Bubble Films. J. Phys. Chem. B 2006, 110 (39), 19537-19542.

(40) Muruganatha; Krastev, R.; Müller, H.-J.; Möhwald, H. Foam Films Stabilized with Dodecyl Maltoside. 2. Film Stability and Gas Permeability. Langmuir 2006, 22 (19), 79817985.

(41) Falls, A. H.; Lawson, J. B.; Hirasaki, G. J. The Role of Noncondensable Gas in Steam Foams. J. Pet. Technol. 1988, 40 (01), 95-104. 
(42) Farajzadeh, R.; Muruganathan, R. M.; Rossen, W. R.; Krastev, R. Effect of Gas Type on Foam Film Permeability and Its Implications for Foam Flow in Porous Media. Adv. Colloid Interface Sci. 2011, 168 (1-2), 71-78.

(43) Nonnekes, L. E.; Cos, S.; Rossen, W. R. Effect of Gas Diffusion on Mobility of Foam for EOR; Society of Petroleum Engineers: SPE, 2012.

(44) Svorstoel, I.; Blaker, T.; Arneson, S.; Holt, T.; Vassenden, F.; M. Surguchev, L. Foam Pilot Evaluations for the Snorre Field, Part 2: Numerical Simulations and Economical Evaluations; 1995.

(45) Farajzadeh, R.; Krastev, R.; Zitha, P. L. J. Foam Films Stabilized with Alpha Olefin Sulfonate (AOS). Colloids Surf. Physicochem. Eng. Asp. 2008, 324 (1-3), 35-40.

(46) Simjoo, M.; Zitha, P. L. J. Effects of Oil on Foam Generation and Propagation in Porous Media; Society of Petroleum Engineers: SPE, 2013.

(47) Simjoo, M.; Nguyen, Q. P.; Zitha, P. L. J. Rheological Transition during Foam Flow in Porous Media. Ind. Eng. Chem. Res. 2012, 51 (30), 10225-10231.

(48) Simjoo, M.; Dong, Y.; Andrianov, A.; Talanana, M.; Zitha, P. L. J. CT Scan Study of Immiscible Foam Flow in Porous Media for Enhancing Oil Recovery. Ind. Eng. Chem. Res. 2013, 52 (18), 6221-6233.

(49) Ma, K.; Ren, G.; Mateen, K.; Morel, D.; Cordelier, P. Modeling Techniques for Foam Flow in Porous Media. SPE J. 2015, 20 (03), 453-470.

(50) Cheng, L.; Reme, A.; Shan, D.; Coombe, D.; Rossen, W. Simulating Foam Processes at High and Low Foam Qualities; Society of Petroleum Engineers: Tulsa, Oklahoma, 2000.

(51) Sedev, R.; Exerowa, D. DLVO and Non-DLVO Surface Forces in Foam Films from Amphiphilic Block Copolymers. Adv. Colloid Interface Sci. 1999, 83 (1-3), 111-136.

(52) Hirasaki, G. Wettability: Fundamentals and Surface Forces. Spe/Doe 1988, 17367.

(53) Zhu, W. Physical Chemistry; Tsinghua University Press, 2008.

(54) Israelachvili, J. Intermolecular and Surface Forces, Second Edition.; Academic Press, 1991.

(55) Kibodeaux, K. Experimental and Theoretical Studies of Foam Mechanisms in Enhanced Oil Recovery and Matrix Acidization Applications, The University of Texas at Austin: Austin, TX, 1997. 